Canadian Studies in Population, Vol. 27(2), 2000, pp. 329-354

\title{
Contributions of Socioeconomic, Sociopsychological and Biological Factors to Fertility Differentials in Canada
}

John Jayachandran

Concordia University College of Alberta

Edmonton, Alberta

\section{Abstract}

Despite the feeling among researchers in Canada that fertility differential by ethnicity, religion, and region are narrowing, these differences are still noticeable. The purpose of this paper to examine the contributions of socioeconomic, sociopsychological and biological factors to these differences. The analysis uses data from the 1984 Canadian Fertility Survey. The results from regression decomposition analysis show that fertility differentials by structural factors have narrowed in recent years. Economic factors, such as couple's standard of living, their financial future and financial success, contribute very little for fertility explanations. Sociopsychological process within the family, measured by gender role egalitarianism and the subjective value of children, shows couple's in joint-role relationships have fewer children and the subjective value of children is positively related to fertility. 
Contributions of Socioeconomic, Sociopsychological and Biological Factors to Fertility Differentials in Canada

\section{Réaumé}

Malgré l'opinion des chercheur(euse)s canadien(ne)s que la fertilité différentielle selon la religion, la region et les groupes éthniques se rétrécit, ces différences-ci se voient toujours. Dans cet article on étudie les contributions à ces différences des facteurs socio-économiques, socio-psychologiques et biologiques. L'analyse emploie les données du Sondage canadien de la fertilité de 1984. Les résultats de l'analyse régression décomposition indiquent que les différentiels de la fertilité ont rétréci ces dernières années. Les facteurs économiques tel que le niveau de vie du couple, leur avenir et leur succès financiers ne contribuent pas aux explications de la fertilité. Le processus sociopsycholgiques de la famille, précisés par l'égalitarianism des rôles du sexe et la valeur subjective des enfants indiquent que les couples des relations rôles-joints ont moins d'enfants et il y a une corrélation positive entre la valeur subjective des enfants et la fertilité.

KeyWords: fertility, socioeconomic factors, sociopsychological factors, regression decomposition.

\section{Introduction}

Researchers in Canada studying fertility focus mainly on fertility in relation to variables such as region, residence, ethnicity, religion and other structural factors. Some of these factors are becoming less important in explaining fertility differentials (Lapierre-Adamcyk in Veevers, 1983, Balakrishnan et.al, 1994; McVey and Kalbach, 1995). Nevertheless, there is a growing need to understand how various socioeconomic, psychological, and biological variables are causally linked to fertility.

It is traditional in demography and sociology to look first at differences arising from structural or background factors. Demographers have long recognized the theoretical inadequacy of most structural explanations (Vance, 1952). According to Turchi (1975b) "reliance solely upon normative arguments in the explanation of fertility differentials is clearly insufficient. Explanations of fertility differentials on the basis of membership in varying social, ethnic, and economic groups have been unimpressive statistically, and, overtime, those differentials which have been discovered have begun to disappear" (p. 14). Similar conclusions are reached by Blake (1966), Jones and Westoff(1979) and Goldscheider and Mosher (1991). 
However, a number of views exist concerning how group membership and fertility are related. The basic sociological notion is that behaviour is, to a large extent, a function of group membership, the persistence of subgroup norms which govern fertility (Lorimer,1954), the power of minority group status to determine reproductive behaviour (Long, 1970; Johnson and Nishida, 1980; Trovato and Burch, 1980; Halli, 1987) and the dominant group over subgroups (Jones and Westoff, 1979; Mosher and Hendershot, 1984).

A number of researchers have indicated the importance of the role of economic variables in fertility analysis (Leibeinstein, 1957; Becker, 1960; Freedman, 1963; Easterlin, 1975; Bachu, 1993). Even though empirical findings are mixed, there is a general consensus that these factors do account for a certain amount of variations in fertility. Other factors such as the subjective assessment of financial situations (savings, financial success, financial planning) by couples and the notion of work commitment also appear to be valid indicators to assess the effect of economic rationality on fertility decision-making (Pinelli, 1971; Safilios-Rothschild, 1972; Sabol, 1974; Suter et al., 1976; Kupinski, 1977; Ryder, 1990).

Researchers have been quite skeptical about the role of sociopsychological factors in fertility; as a result only a handful of studies is available in this area (Scanzoni, 1976; Goldscheider and Waite, 1991). Bagozzi and Van Loo (1980) studied fertility as a process of social exchange or influence occurring within the family. The model developed by them takes the husband and wife relationship as the unit of analysis and emphasizes the couple's interactions. The social exchange is measured by the degree of gender role egalitarianism between husband and wife. They found that the more the husband and wife desire the rewards associated with egalitarian marriages, the less they will desire the benefits that accompany additional children.

Another factor often involved in the fertility decision-making process is the value of children to parents. Parents' perceptions of the costs and benefits of children and the value they attach to these costs and benefits constitute their general attitude toward having children. The value of children to parents may be economic or psychological. A great deal of research has been devoted to identifying and measuring the perceived costs and benefits (both economic and noneconomic) of children (Blake, 1968; Hawthorne, 1970; Fawcett, 1972; Hoffman and Hoffman, 1973; Arnold et al., 1975; Scanzoni, 1975; Bulatao, 1981). Studies based on developed countries (e.g., Fawcett, 1972) report that respondents on the benefit side see children as providers of love and companionship, as a source of fun and excitement. On the negative side (cost), children place constraints on one's freedom and flexibility, cause heavy financial burden; and create stress between husband and wife. In general, whatever increases the cost of rearing children or reduces the benefit of children operates to reduce fertility. 
With greater emphasis on the social, economic and, to some extent, psychological variables in studying the determinants of fertility, biological variables receive little attention unless they enter into the theoretical model as explanatory or conditioning variables. Biological factors such as intercourse variables, conception variables, and gestation variables, however, mediate the effects of basic determinants of fertility (Davis and Blake, 1956; Bongaarts, 1982).

Despite the feeling among researchers in Canada that fertility differentials by ethnicity, religion and region are narrowing, these differences are still noticeable. Therefore, the intent of this paper is to examine the contributions, if there is any, of socioeconomic, sociopsychological and biological factors to these differences.

\section{Data and Methodology}

The data for the study come from the Canadian Fertility Survey (CFS), which was conducted from April to June of 1984. This survey provides information necessary on socioeconomic, sociopsycholgical, and biological factors to test various theoretical hypotheses. The target population was women of all marital statuses in their reproductive years of $18-49$, who were accessible by means of a residential telephone number and able to converse over the phone in either English or French. The detailed methodological aspects of the survey are given by Trembley and Trudel (1984). The final sample included 5,315 women.

The primary dependent variable used in this study is current family size. This variable is bound to be influenced by age, therefore, in this analysis the age effect is removed. This has been done by measuring each women's fertility as the deviation from the mean for her age. This approach is similar to Multiple Classification Analysis used to adjust for age effect.

The independent variables used in this study can be classified under socioeconomic, sociopsychological and biological variables. The rationale for inclusion of these variables stems from the theoretical and empirical literature reviews. Detailed description of the concepts and indicators used in the analysis is given in table 1.

The main approach taken here is a regression decomposition model developed by Coleman et al. (1972). The rationales for using this approach are two folds: 1) the preliminary analysis suggested the presence of interactions of structural factors (ethnicity, religion, region) with other variables; and 2) this approach is useful in testing any competing hypotheses. In the present study the purpose is to examine whether fertility differentials between groups (ethnicity, religion and 
Table 1

Description of Concepts and Indicators

\section{Concepts/Variables}

Description

\section{Socioeconomic}

Residence
Region
Religion
Ethnicity
Women's education
Work commitment

Financial status

\author{
Residence in youth (1=rural...3=big city) \\ $1=$ Atlantic $0=$ Rest of Canada \\ $1=$ Catholic $0=$ non-catholic \\ 1= British 2=French 3=Other \\ Women's education in years \\ Number of work interruptions \\ (High score $=$ Iower commitment to work) \\ -Feeling of financial success \\ -Financial plan for the future \\ -Savings for the future \\ -Standard of living \\ (High score $=$ better financial status)
}

\section{Sociopsychological}

Gender Role

Egalitarianism (GRE)

Cost-benefit of children
Sharing of household chores (housework, childcare, school work, financial decision-making etc)

(High score $=$ greater egalitarianism)

\section{Psychological cost of children}

-children distance the spouses

-parenting means heavy responsibility

- reduce work opportunity outside home

Psychological benefit of children

- goal/affection/happiness in life

(High score $=$ greater psychological cost than benefit of having children)

\section{Biological}

Age at first marriage

Fertility planning

Birth interval
Age at first marriage in years

Use of contraceptives in planning fertility (High score =perfect planning of fertility) First birth interval in years 
region) will disappear when various socioeconomic, sociopsychological and biological factors are statistically controlled. According to Coleman et al. (1972), the observed differences in average family size $\left(Y_{B}-Y_{0}\right)$ between British (B) and others $(\mathrm{O})$ can be decomposed into the following four components: ${ }^{2}$

$$
\begin{aligned}
& \left(Y_{B}-Y_{O}\right)=1 / 2 \sum\left(b_{i B}+b_{1 O}\right)\left(\bar{X}_{i B}-\bar{X}_{1 O}\right)+\ldots \ldots \ldots \ldots . . .(A)
\end{aligned}
$$

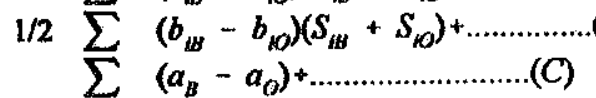

$$
\begin{aligned}
& 1 / 2 \sum\left(b_{i B}-b_{o}\right)\left(\bar{X}_{i B}-S_{i B}+\bar{X}_{i O}-S_{i O}\right) \ldots \ldots(
\end{aligned}
$$

The $b_{i}$ 's are multiple regression coefficients obtained by regressing the dependent variable on all independent variables for each ethnic group; and the $X_{i}$ and $S_{i}$ refer to the means and standard deviations; a's refer to the intercepts in the equations. The subscripts $B$ and $O$ refer to British and Other ethnic groups respectively.

Component A presents the effect due to mean differences in structural variables. This component shows whether the equalization of the variable means $\left(\mathrm{X}_{\mathrm{i}}\right)$, weighted by the corresponding average regression coefficients $\left(b_{i}\right)$, will lead to equalization of fertility. If the overall value derived from this component is positive or negative, the interpretation is that compositional differences do account for a portion of observed fertility differences. A negative value implies a lowering of fertility differences. A zero value means that the observed fertility differences are not due to compositional differences (Trovato and Burch, 1980).

Component $\mathrm{B}$ represents the difference in regression slopes or the interaction effect of ethnic groups with the independent variables in the analysis. A value other than zero (negative or positive) means that ethnic groups interact with the compositional variables. A positive value indicates that the net effect of differences in the $b_{i}$ is to raise fertility of a given ethnic group in comparison to the reference group (British), independent of the other types of effects. A negative value has similar but opposite interpretation.

Component $\mathrm{C}$ is the difference between intercepts, providing the main effect of ethnicity on fertility. A positive value means that the net effect of the ethnicity is to lower fertility below the reference group independent of interaction (B) and compositional differences (A). A negative value will have similar but opposite interpretation. Thus, a non-zero difference means that even if the two groups had identical means on the various independent variables, and even if the effects of these variables (as represented by $b_{i}$ ) were identical, the family size of the two groups would differ by that amount (Jiobu and Marshall, 1977). The last term (D) represents that part of the fertility differentials due to unmeasured variables. It is analogous to error term in regression analysis. A negative value indicates 
that the impact of unmeasured variables would be to decrease ethnic groups' fertility relative to the reference group.

The decomposition analysis tries to separate out the proportion of the difference in dependent variable (fertility) between groups due to different values of the independent variables (variable effect), the proportion due to the different effects of the independent variables (interaction effect), and due to unmeasured variables (error term).

\section{Findings}

The preliminary analysis showed significant differences in fertility by ethnicity, religion, and region. The following section will examine whether fertility differentials by these subgroups will disappear when statistically controlled for various socioeconomic, sociopsychological, and biological factors. The discussion will include the effects of individual variables and their respective concepts (see Appendix 2 for combined effects of factors).

Ethnic Differences

Canadian censuses show the existence of significant fertility differentials for the various ethnic groups (Statistics Canada, 1993; Dumas, 1994). Even though there have been some shifts reflective of the changing character of immigration to Canada, the relative positions of British and French origin with respect to their completed fertility have remained remarkably constant, with the exception of the younger age groups for the French origin (McVey and Kalbach, 1995). More specifically, according to the 1991 census, the French origin reported cumulative fertility lower than the British origin for the entire childbearing age range.

Table 2 presents means and standard deviations of selected variables by ethnic groups and marriage duration. ${ }^{3} \quad$ It is evident from the table that average family size is higher for French respondents than for British. The difference is more pronounced for respondents married longer than 14 years (-.151). Among respondents in the 'other' category (i.e., other western Europeans, eastern Europeans, Asians, Africans and others), average family size is lower than the British for those married less than 14 years $(.067)$ while it is higher for those married longer than 14 years $(-.097)$. The difference in average family size between the British and the French and others can be attributed to differences in variable level means. For example, the factors apparently conducive to higher fertility among the French include: growing up in less urbanized areas, lower education, lesser psychic cost of children, and shorter first birth interval. Among respondents in the 'other' ethnic group, factors such as lower number of work interruptions, greater gender role egalitarianism and higher age at first marriage act to keep their fertility level lower than the British for recently married women. On the other hand, lower education, lesser psychic cost of children and 
Contributions of Socioeconomic, Sociopsychological and Biological Factors to Fertility Differentials in Canada

Table 2

Means and Standard Deviations for Study Variables by Marriage Duration and Ethnicity for Canada: 1984*

\begin{tabular}{lcccccc}
\hline \multirow{2}{*}{ Variables } & \multicolumn{3}{c}{ LE 14 Years } & \multicolumn{3}{c}{ 14+ Years } \\
\cline { 2 - 7 } & British & French & Others & British & French & Others \\
\hline Fertility & 0.151 & 0.219 & 0.084 & 0.179 & 0.330 & 0.276 \\
& $(.778)$ & $(.868)$ & $(.916)$ & $(1.316)$ & $(1.165)$ & $(1.343)$ \\
Residence & 2.147 & 1.867 & 2.197 & 2.060 & 1.833 & 2.061 \\
& $(.778)$ & $(.792)$ & $(.810)$ & $(.809)$ & $(.801)$ & $(.807)$ \\
Women's Education & 13.137 & 12.652 & 13.086 & 12.455 & 10.601 & 12.008 \\
& $(2.541)$ & $(2.556)$ & $(2.601)$ & $(2.836)$ & $(3.053)$ & $(2.986)$ \\
Work Commitment & 2.436 & 2.424 & 2.363 & 2.569 & 2.571 & 2.474 \\
& $(.813)$ & $(.806)$ & $(.835)$ & $(.797)$ & $(.847)$ & $(.835)$ \\
Financial Status & 4.479 & 4.653 & 4.474 & 4.441 & 4.657 & 4.474 \\
& $(.779)$ & $(.851)$ & $(.862)$ & $(.841)$ & $(.858)$ & $(.826)$ \\
Gender Role Egalitarinuisis! & 2.527 & 3.017 & 2.751 & 2.024 & 2.097 & 1.910 \\
& $(1.451)$ & $(1.496)$ & $(1.515)$ & $(1,338)$ & $(1.454)$ & $(1.263)$ \\
Cost-Benefit of Children & -0.533 & -1.004 & -0.664 & -0.369 & -0.851 & -0.497 \\
& $(1.064)$ & $(1.045)$ & $(.969)$ & $(1.162)$ & $(1.068)$ & $(1.023)$ \\
Age at Marringe & 21.639 & 21.684 & 21.795 & 20.221 & 20.834 & 20.599 \\
& $(3.337)$ & $(2.879)$ & $(3.476)$ & $(2.798)$ & $(3.102)$ & $(2.902)$ \\
Fertility Plauning & 0.774 & 0.842 & 0.768 & 0.690 & 0.724 & 0.708 \\
& $(.333)$ & $(.273)$ & $(.337)$ & $(.335)$ & $(.324)$ & $(.323)$ \\
Birth Interval & 2.673 & 2.354 & 2.618 & 2.533 & 1.817 & 2.227 \\
& $(3.104)$ & $(2.373)$ & $(2.877)$ & $(3.230)$ & $(2.783)$ & $(2.825)$ \\
\hline
\end{tabular}

*Standard deviations are in parentheses.

shorter birth interval in the 'other' ethnic group may serve to raise the respondents' fertility level above the British for women married longer than 14 years. However, we need to examine the hypothesis that the difference in average family size by ethnic groups is due to their differences in variable level means. In testing this, we keep the British as the reference group.

Table 3 presents the results of the regression decomposition analyses. ${ }^{4}$ The subtotals for component A suggest, in general, that the adjustment for differences in variable level means would result reduction in fertility. The effects of particular variables in the decomposition suggest that residence $(-.015)$, cost-benefit of children ( -.013$)$, birth interval $(-.048)$ and gender role egalitarianism (.046) are relevant for French women married less than 14 years. For the first three variables, equalization leads to a decline in fertility, while for gender role egalitarianism it increases. Among the French respondents married for 14 or more years, equalization of education $(-.027)$, cost-benefit $(-.032)$ and birth interval $(-.110)$, serve to reduce fertility, while the equalization of age at marriage produces significant increase of fertility (.078). On the other hand, 
gender role egalitarianism (.025), age at marriage (.018), and, to some extent, number of work interruptions (.011) are important for respondents in the 'other' category married for less than 14 years. Equalization in all the variables, except birth interval, acts to increase fertility. Similar adjustments for respondents married 14 years or longer show that age at marriage (.042) and number of work interruptions (.013) serve to increase fertility while the adjustment for birth interval $(-.001)$ has the opposite effect. In general, the equalization of variable means to those of the British produces a significant reduction in fertility for the French (-.058) and more so for respondents married for 14 years or longer.

The combined effects for ethnicity, given in Appendix 2, suggest that sociopsychological factors contribute slightly more to understand ethnic differences in fertility, followed by biological and socioeconomic factors. Among respondents married for 14 or more years, adjustments for sociopsychological factors produce reduction in fertility. This may be mainly due to differences on the value of children (cost-benefit) between the British and 'others' (French and others). Among respondents married for less than 14 years, similar adjustments would result in increase of fertility. This may be attributed to differences in gender-role egalitarianism; the French and the 'other' ethnic groups have greater egalitarianism than the British (see Table 2). With regard to biological factors, equalization, in general, would lead to a decline in fertility. However, the results of individual variables, as discussed earlier, are mixed. The positive effect of age at marriage is offset by the negative effect of birth interval on fertility. This is more pronounced among respondents married for 14 or more years.

Component $\mathrm{C}$, the difference between intercepts, exhibits the main effect or the effect of ethnicity per se on fertility. The results indicate that the independent effect of ethnicity is to raise fertility for respondents married fewer than 14 years, while it serves to lower fertility for their counterparts. The effect of ethnicity on fertility is much stronger for those married for a longer period of time. Ethnicity alone would decrease the fertility of the French and 'other' by 1.00 and 1.29 respectively. On the other hand, it is interesting to note that ethnicity serves to increase the fertility of the French $(-.294)$ and 'other' $(-.191)$ among the recently married women. However, the final outcome (i.e. the actual difference in family size between the British and 'other' ethnic groups) in three of the four categories are different from what the ethnic effect or main effect suggests. This difference, then, implies that in addition to ethnicity there may be other factors operating to produce a given family size for a particular ethnic group.

The comparison of subtotals in Table 3 for main and interaction effects suggest that the interaction component $B$ is relatively smaller than the main effect (C) of ethnicity, and more so for respondents married for 14 years or longer. The 
Table 3

Regression Decomposition of Current Family Size (Net Age) by Ethnicity for Canada: 1984

\begin{tabular}{|c|c|c|c|c|}
\hline & \multicolumn{2}{|c|}{ LE 14 YEARS } & \multicolumn{2}{|c|}{ 14+ YEARS } \\
\hline & French & Others & French & Others \\
\hline Actual difference (British-Others) & -0.068 & 0.067 & -0.151 & -0.097 \\
\hline \multicolumn{5}{|l|}{ Variable levels (A) } \\
\hline Residence & -0.015 & 0.002 & 0.004 & 0.000 \\
\hline Women's Education & 0.004 & 0.000 & -0.027 & $-0,008$ \\
\hline Work Commitment & 0.002 & 0,011 & 0.000 & 0.013 \\
\hline Financial Status & -0.003 & 0.000 & 0.016 & 0.005 \\
\hline Gender Role Egalitarianism & 0.046 & 0.025 & 0.005 & -0.009 \\
\hline Cost-benefit of Children & -0.013 & 0.000 & -0.032 & -0.005 \\
\hline Age at Marriage & 0.005 & 0.018 & 0.078 & 0.042 \\
\hline Fertility Planning & -0.001 & 0.000 & 0.001 & -0.001 \\
\hline Birth Interval & -0.048 & -0.008 & -0.110 & -0.046 \\
\hline Subtotal & -0.022 & 0.049 & -0.058 & -0.010 \\
\hline Differences between intercepts (C) & -0.294 & -0.191 & 0.997 & 1.287 \\
\hline \multicolumn{5}{|l|}{$\begin{array}{l}\text { Variable effects (B) } \\
\text { (Interaction; ethnicity with variables) }\end{array}$} \\
\hline Residence & 0.120 & 0.101 & 0.158 & 0.180 \\
\hline Women's Education & 0.046 & 0.050 & -0.131 & -0.114 \\
\hline Work Commitment & -0.006 & -0.007 & -0.095 & -0.088 \\
\hline Financial Status & 0.016 & 0.010 & -0.078 & 0.032 \\
\hline Gender Role Egalitarianism & -0.012 & 0.040 & $-0,208$ & -0.156 \\
\hline Cost-benefit of Children & 0.075 & 0.019 & 0.038 & -0.022 \\
\hline Age at Marriage & -0.064 & -0.077 & -0.055 & -0.141 \\
\hline Fertility Planning & 0.059 & 0.040 & 0.180 & -0.046 \\
\hline Bitth Interval & 0.006 & -0.019 & 0.111 & 0.104 \\
\hline Subtotal & 0.239 & 0.157 & -0.080 & -0.250 \\
\hline Unmeasured (D) & 0,009 & 0.052 & -1.010 & -1.124 \\
\hline Total & -0.068 & 0.067 & -0.151 & -0.097 \\
\hline
\end{tabular}


subtotals reveal that ethnicity interacts with other variables to reduce fertility for respondents married 14 or more years $(-.080,-.250)$ and to increase fertility for more recently married women $(.239, .157)$. Among the respondents married less than 14 years, residence, education, cost-benefit, fertility planning, gender role egalitarianism (for the 'other' ethnic group) and age at first marriage are more important factors. Except for age at first marriage, the remaining five variables interact with ethnicity to increase average family size. For respondents married 14 or more years, all the variables exhibit significant interactions. The results also suggest that even though residence, fertility planning and birth interval interact strongly to increase fertility, their influence is offset by the negative effect of remaining variables for the French women. Similarly, for the respondents classified under the 'other' ethnic group, residence, financial status, and birth interval are the only variables appear to have positive influence on fertility. Note, however, that residence and birth interval serve systematically to increase fertility in both the French and 'other' groups. On the other hand, education, work interruptions, gender role egalitarianism and age at marriage interact consistently with ethnicity to decrease average family size. Thus, an understanding of the effects of individual variables is important, even though the outcomes of the interactions are negligible.

The combined effects (Appendix 2) suggest that the socioeconomic factors interact with ethnicity to increase fertility among respondents married for less than 14 years. The effect of sociopsychological factors, on the other hand, is to decrease fertility among respondents married for 14 or more years. For the French respondents the biological factors interact with other variables to increase fertility, more specifically among respondents married for 14 or more years.

The unmeasured component $\mathrm{D}$, although it has no substantive interpretation, appears to be substantial for women married 14 or more years, whereas for women married less than 14 years this component is almost nonexistent. Furthermore, the error components are related to fertility in opposite directions for these two group of women.

The data presented in this study demonstrate that ethnicity has different consequences for women married recently than for those married for a longer period of time. Most surprisingly, the evidence suggests that ethnicity per se not only increases fertility, but interacts with other variables to maintain higher levels of reproduction than the British for recently married women. However, the current family size provides support only for the French women. For women in the 'other' ethnic group, the fertility level is relatively lower than that of the British. These differences can be attributed to lower variable means, especially on socioeconomic factors, for the French and higher variable means for the others in relation to the British. The equalization of variable means to those of the British, however, produces only minor adjustments. 
Among the respondents married 14 years or longer, ethnicity per se serves to lower fertility and interacts with other variables to maintain a lower level of fertility. The current family size for this group of women, however, seems to be higher than for the British. Furthermore, the equalization of variable means to those of the British are not large enough to attribute the observed difference to the differences in the variable levels. Consequently, a substantial portion of variance remains unexplained.

The decomposition analysis for ethnicity suggests that equalization of variable means contribute very little to understand fertility differences. However, the interaction effects reveal that socioeconomic factors are relevant for recently married women; sociopsychological and biological factors for women married for 14 or more years.

\section{Religious Differences}

The significance of religious differentials in fertility has been investigated by many researchers (Henripin, 1972; William and Zimmer, 1990; Goldscheider and Mosher, 1991). A great deal of attention has been focused on the comparison between Protestants and Catholics. These comparisons have generally shown higher levels of fertility for the latter group. More recently, however, studies have suggested that the longtime differences between Protestant and Catholic fertility levels have nearly disappeared, especially among recent birth cohorts (Williams and Zimmer, 1990; Goldscheider and Mosher, 1991; Balakrishnan et al., 1994)

Table 4 presents means and standard deviations of all the variables in the analysis by religion and marital duration. Catholics, in general, have higher average family size than non-Catholics. Moreover, the difference between these two religious groups is relatively larger for those married 14 or more years (.108) than for those married less than 14 years $(.011)$. With regard to variable means, non-Catholics score relatively higher on residence, education and birth interval, whereas Catholics score higher on financial status, gender role egalitarianism, cost-benefit of children, age at marriage and fertility planning (particularly for women married less than 14 years). These differences in variable means suggest that we may be able to explain some of the observed fertility differences between these two groups through standardization.

The subtotals for component $\mathrm{A}$ from the decomposition analysis (table 5) suggest that equalization of variable means of the non-Catholics to those of the Catholics would increase fertility, and to a greater degree among women married 14 or more years (.050). ${ }^{4}$ Closer examination of individual contributions made by the variables demonstrates the presence of offsetting effects. Among the recently married women, equalization of residence (.012) and birth interval (.052) raises fertility, while equalization of gender role 
egalitarianism (-.034) and age at marriage (-.023) decreases fertility. Similarly, among the women married 14 or more years, financial status $(-.013)$, gender role egalitarianism $(-.011)$ and age at marriage $(-.066)$ act to decrease fertility; the cost-benefit of children (.028) and birth interval (.100) serve to increase fertility. Incidentally, the non-Catholics have lower current fertility than the Catholics, but their fertility level can be reduced further if adjustments are made on some of the variables. Note, however, that the longer first birth interval and the greater cost associated with children among the non-Catholics seem to be the crucial factors in their current low level of fertility.

Table 4

Means and Standard Deviations for Study Variables by Marriage Duration and Religion for Canada: 1984*

\begin{tabular}{lcccc}
\hline \multirow{2}{*}{ Variables } & \multicolumn{2}{c}{ LC 14 Years } & \multicolumn{2}{c}{ 14+ Years } \\
\cline { 2 - 5 } & Catholic & Non-Catholic & Catholic & Non-Catholic \\
\hline Fertility & 0.161 & 0.150 & 0.305 & 0.197 \\
& $(.882)$ & $(.927)$ & $(1.370)$ & $(1.200)$ \\
Residence & 1.996 & 2.152 & 1.936 & 2.054 \\
& $(.808)$ & $(.799)$ & $(.809)$ & $(.810)$ \\
Atlantic & 0.096 & 0.099 & 0.092 & 0.089 \\
& $(.295)$ & $(.299)$ & $(.290)$ & $(.285)$ \\
Women's Edtucation & 12.564 & 13.132 & 10.992 & 12.388 \\
& $(2.559)$ & $(2.582)$ & $(2.992)$ & $(2.888)$ \\
Work Commitment & 2.414 & 2.416 & 2.561 & 2.513 \\
& $(.830)$ & $(.835)$ & $(.843)$ & $(.811)$ \\
Financial Status & 4.622 & 4.430 & 4.576 & 4.455 \\
& $(.843)$ & $(.847)$ & $(.864)$ & $(.819)$ \\
Gender Role Egalitarianisn & 2.958 & 2.634 & 2.103 & 1.929 \\
& $(1.518)$ & $(1.481)$ & $(1.424)$ & $(1.260)$ \\
Cost-benefit of Children & -0.933 & -0.562 & -0.792 & -0.338 \\
& $(1.000)$ & $(1.035)$ & $(1.027)$ & $(1.101)$ \\
Age at Marringe & 21.786 & 21.581 & 20.851 & 20.256 \\
& $(3.193)$ & $(3.360)$ & $(2.993)$ & $(2.806)$ \\
Fertility Planning & 0.810 & 0.770 & 0.717 & 0.703 \\
& $(.307)$ & $(.331)$ & $(.325)$ & $(.329)$ \\
Birth Interval & 2.296 & 2.642 & 1.872 & 2.490 \\
& $(2.588)$ & $(3.018)$ & $(2.530)$ & $(3.200)$ \\
\hline
\end{tabular}

*Standard deviations are in parentheses.

The combined effects (Appendix 2) suggest that sociopsychological and biological factors appear to contribute, to some extend, to observed differences in fertility. While the equalization of sociopsychological factors acts to decrease fertility for the recently married women $(-.032)$, the biological factors act to increase fertility among women married for a longer period of time (.033). 
Table 5

Regression Decomposition of Current Family Size (Net Age) by Religion for Canada: 1984

\begin{tabular}{|c|c|c|}
\hline & LE 14 Years & $14+$ Years \\
\hline Actual difference (Catholics - Non-Catholics) & -0.068 & 0.067 \\
\hline \multicolumn{3}{|l|}{ Variable levels (A) } \\
\hline Residence & 0.012 & 0.003 \\
\hline Atlantic & -0.000 & 0.002 \\
\hline Women's Education & -0.003 & 0.002 \\
\hline Work Commitment & -0.000 & 0.007 \\
\hline Financial Status & 0.002 & -0.013 \\
\hline Gender Role Egalitarianism & -0.034 & -0.011 \\
\hline Cost-benefit of Children & 0.003 & 0.028 \\
\hline Age at Marriage & -0.023 & -0.066 \\
\hline Fertility Planning & 0.002 & -0.001 \\
\hline Birth Interval & 0.052 & 0.100 \\
\hline Subtotai & 0.009 & 0,050 \\
\hline Differences between intercepts (C) & -0.550 & 0.112 \\
\hline \multicolumn{3}{|l|}{$\begin{array}{l}\text { Variable effects (B) } \\
\text { (Interaction: religion with variables) }\end{array}$} \\
\hline Residence & -0.069 & 0.045 \\
\hline Atlantic & 0.083 & 0.178 \\
\hline Women's Education & -0.043 & 0.131 \\
\hline Work Commitment & -0.024 & 0.094 \\
\hline Financial Status & 0.015 & -0.091 \\
\hline Gender Role Egalitarianism & 0.034 & 0.009 \\
\hline Cost-benefit of Children & -0.019 & -0.076 \\
\hline Age at Marriage & 0.127 & 0.007 \\
\hline Fertility Planning & -0.015 & -0.235 \\
\hline Birth Interval & 0.028 & $-0,179$ \\
\hline Subtotal & 0.116 & -0.117 \\
\hline Unmensured (D) & 0.436 & 0.063 \\
\hline Total & 0.011 & 0.108 \\
\hline
\end{tabular}


The main effect of religion is to increase fertility for the recently married (-.550) and to decrease it for those married longer than 14 years (.112). This finding is rather unexpected. One would normally expect the respondents married for 14 or more years to have been married at a younger age than the recently married, and to hold pronatal values. But this does not seem to be the case for the present study. Surprisingly, the effect of religion per se is substantial for the recently married non-Catholics (-.550) and serves to increase their fertility. However, their current family size is relatively lower than the Catholics'. This means that there may be other factors operating to maintain their current low level of fertility.

The interaction component $B$ also produces results similar to those of the main effect of religion. The subtotals of the interaction component suggest that religion interacts with other variables in the model to increase fertility for the recently married (.116) and to decrease it for those married for a longer period of time (-.117). Among the recently married women, the interaction effects of residence (-.069), education (-.043), Atlantic (.083), gender role egalitarianism $(.034)$ and age at marriage $(.127)$ are relatively greater. The first two variables serve to reduce the average family size for the non-Catholics while the next three variables act to raise average family size. On the other hand, among the women married 14 years or longer, all the variables, except gender role egalitarianism and age at marriage, exhibit strong interaction effect with religion. Note, however, that only four of these variables - financial status $(-.091)$, cost-benefit of children $(-.076)$, fertility planning $(-.235)$ and birth interval (-.179) -interact to reduce fertility. There are some differences between the recently married and their counterparts in terms of the interaction effect of a given variable. Residence, for example, interacts with religion to reduce fertility for the recently married (-.069), while it increases fertility for those married 14 or more years (.045). A similar pattern emerges for education and work interruptions. Financial status and birth interval serve to lower the fertility of those married for a longer period of time; but the opposite is true for the recently married women. Among the respondents in the Atlantic provinces religion interacts to increase fertility, irrespective of marital duration.

Appendix 2 shows that the interaction of biological factors with religion contributes more to understand fertility differences. Socioeconomic factors also appear to be important among women married for a longer period of time.

In sum, the analysis suggests that equalization of variable means produces very minor adjustments. Surprisingly, for the recently married women religion per se not only serves to increase fertility but interact with other variables to raise fertility. The reverse holds true for respondents in longer marital union. Biological factors, in general, appear to contribute more to understand fertility differentials (see Appendix 2). The results also indicate that a substantial portion of variance remains unexplained for the recently married women. 


\section{Regional Differences}

In Canadian fertility studies, region plays an important role in understanding fertility differentials. Although regional differences in fertility appear to be narrowing, they remain noticeable. For example, the eastern regions, Saskatchewan, and the Yukon and Northwest Territories have fertility levels above the national average. Researchers have documented these regional differences (Henripin, 1972; Mathews, 1976; Balakrishnan et al., 1979; Trovato and Halli, 1983).

Table 6 presents means and standard deviations of the variables in the analysis by region and marital duration. It is quite evident from the table that Atlantic women have relatively higher average family size than women living elsewhere in Canada. Moreover, the difference is greater for women married 14 years or longer (.773) than for recently married women (.232).

Table 6

Means and Standard Deviations for Study Variables by Marriage Duration and Region for Canada: $1984^{*}$

\begin{tabular}{lcccc}
\hline \multirow{2}{*}{ Variables } & \multicolumn{2}{c}{ LE 14 Years } & \multicolumn{2}{c}{ 14+ Years } \\
\cline { 2 - 5 } & Rest of Canada & Atlantic & Rest of Canada & Attantic \\
\hline Fertility & 0.133 & 0.365 & 0.177 & 0.950 \\
& $(.904)$ & $(.899)$ & $(1.173)$ & $(1.958)$ \\
Residlence & 2.101 & 1.853 & 2.024 & 1.751 \\
& $(.811)$ & $(.735)$ & $(.816)$ & $(.176)$ \\
Catholic & 0.482 & 0.474 & 0.468 & 0.477 \\
& $(.500)$ & $(.501)$ & $(.499)$ & $(.501)$ \\
Women's Education & 1.941 & 12.093 & 11.786 & 11.210 \\
& $(2.577)$ & $(2.551)$ & $(3.037)$ & $(2.780)$ \\
Work Commitment & 2.403 & 2.520 & 2.514 & 2.754 \\
& $(.823)$ & $(.905)$ & $(.813)$ & $(.924)$ \\
Financial Status & 4.523 & 4.514 & 4.515 & 4.477 \\
& $(.852)$ & $(.833)$ & $(.834)$ & $(.923)$ \\
Gender Role Egalitarianism & 2.803 & 2.670 & 2.013 & 1.979 \\
& $(1.513)$ & $(1.455)$ & $(1.340)$ & $(1.365)$ \\
Cost-Benefit of Children & -0.736 & -0.785 & -0.548 & -0.577 \\
& $(1.038)$ & $(1.010)$ & $(1.100)$ & $(0.990)$ \\
Age at Marriage & 21.750 & 21.039 & 20.585 & 20.034 \\
& $(3.310)$ & $(2.939)$ & $(2.929)$ & $(2.663)$ \\
Fertility Planning & 0.793 & 0.758 & 0.713 & 0.669 \\
& $(.319)$ & $(.326)$ & $(.328)$ & $(.319)$ \\
Birth Interval & 2.542 & 1.862 & 2.275 & 1.454 \\
& $(2.813)$ & $(2.858)$ & $(2.959)$ & $(2.390)$ \\
\hline
\end{tabular}

* Standard deviations are in parentheses. 
Atlantic women, in general, are less educated, live in less urbanized areas, interrupt their work more often, feel less economically successful and have a poorer standard of living than other Canadian women. They also maintain lower egalitarianism at home and associate a lower subjective cost with having children. In addition, Atlantic women marry at a relatively younger age, use contraceptives less often in planning their pregnancies, and are likely to have a shorter first birth interval than women outside this region. Essentially, all these indicators promote higher fertility in the Atlantic region.

Appendix 2 shows that adjustment to socioeconomic, sociopsychological, and biological factors would reduce family size in the Atlantic region. Among the three factors, biological factors contribute more to understand fertility differentials in this region.

The subtotals of component A suggest that there would be a fertility reduction of .232 and .335 for Atlantic women recently married and married for 14 or more years, respectively, if their variable levels were equalized to the means of women elsewhere in the country (Table 7 ). ${ }^{4}$ The variables most likely to contribute to the reduction for most recently married women are residence ($.033)$, age at marriage $(-.080)$, birth interval $(-.089)$ and, to a certain extent, work interruptions (-.018) and gender role egalitarianism (-.016). Similarly, among the women married 14 or more years, work interruptions (-.046), age at marriage $(-.079)$, birth interval $(-.205)$ and financial status $(-.012)$ are likely to reduce fertility. Note, however, that equalization of residence (.015) increases the fertility for this group of women. It is evident from the table that adjustment for age at marriage and birth interval alone would substantially reduce fertility for Atlantic women, irrespective of marital duration.

Component $\mathrm{C}$ suggests that, in comparison to the rest of Canada, the independent effect of residence in the Atlantic region serves to raise fertility by .210 of a child for recently married respondents and by 4.089 for those married 14 years or longer. The magnitude of the regional effect is substantial in the latter case. Moreover, this effect for the second group is greater than the subtotals of component A, thus indicating that there may be other factors responsible for this region's higher fertility.

The interaction effects given in Appendix 2 show that biological factors produce one of the strongest effects (.712) among the three factors. While the effects of both the socioeconomic and sociopsychological factors are consistent across marital duration, the effects of biological factors are mixed.

According to the interaction component, the subtotals reveal that region interacts with other variables to reduce average family size for the recently married $(-.184)$, while it interacts to raise family size for those married 14 or 
Table 7

Regression Decomposition of Current Family Size (Net Age) by Region for Canada: 1984

\begin{tabular}{|c|c|c|}
\hline & LE 14 Years & $14+$ Years \\
\hline Actual difference (Rest of Canada - Atlantic) & -0.232 & -0.773 \\
\hline \multicolumn{3}{|l|}{ Variable levels (A) } \\
\hline Residence & -0.033 & 0.015 \\
\hline Catholic & 0,001 & -0.003 \\
\hline Women's Education & -0.002 & -0.003 \\
\hline Work Commitment & -0.018 & -0.046 \\
\hline Financial Status & 0.000 & -0.012 \\
\hline Gender Role Egalitarianism & -0.016 & -0.004 \\
\hline Cost-benefit of Children & 0,000 & -0.001 \\
\hline Age at Marriage & -0.080 & -0.079 \\
\hline Fertility Planning & 0.004 & 0.004 \\
\hline Birth Interval & -0.089 & -0.205 \\
\hline Subtotal & -0.232 & -0.335 \\
\hline Differences between intercepts (C) & -0.210 & -4.089 \\
\hline \multicolumn{3}{|l|}{$\begin{array}{l}\text { Variable effects (B) } \\
\text { (Interaction: religion with variables) }\end{array}$} \\
\hline Residence & 0.095 & -0.159 \\
\hline Catholic & -0.1 .63 & -0.310 \\
\hline Women's Education & 0.035 & 0.045 \\
\hline Work Commitment & -0.009 & -0.128 \\
\hline Financial Status & 0.022 & 0.497 \\
\hline Gender Role Egalitarianism & 0.061 & 0.192 \\
\hline Cost-benefit of Children & -0.041 & -0.006 \\
\hline Age at Marriage & -0.011 & 0.204 \\
\hline Fertility Planning & -0.043 & -0.087 \\
\hline Birth Interval & -0.130 & 0.599 \\
\hline Subtotal & -0.184 & 0.849 \\
\hline Unmensured (D) & 0.393 & 2.802 \\
\hline Total & -0.232 & -0.773 \\
\hline
\end{tabular}


more years. The effects of individual variables show that the interactions are substantial for all the variables, except for work interruptions and age at marriage among the recently married, and cost-benefit of children for those married 14 or more years. For the recently married women, religion (-.163), cost-benefit $(-.041)$, fertility planning $(-.043)$ and birth interval $(-.130)$ interact with region to reduce fertility, while residence $(.095)$, education $(.035)$, financial status $(.022)$ and gender role egalitarianism (.061) serve to raise family size. Similarly, among women married for 14 or more years, residence (-.156), religion $(-.310)$, work interruptions $(-.128)$ and fertility planning $(-.087)$ act to lower fertility, while education (.045), financial status $(.497)$, gender role egalitarianism (.192), age at marriage (.204), and birth interval (.600) serve to raise fertility.

The unmeasured component is higher than any other for the recently married women (.393), whereas among the women married 14 or more years, it ranks second (2.802) to the main effect of region, but is still substantial. In both groups, these unmeasured factors would enable Atlantic women to have higher fertility. In general, the findings suggest that equalization of variable means would lead to fertility reductions among the Atlantic females. Region by itself serves to raise fertility, but more so women married for 14 years or longer; it also interacts with other variables to increase the fertility of the latter and to decrease the fertility of recently married women.

\section{Conclusions}

The results from the decomposition analysis for ethnicity suggest the following. Socioeconomic, sociopsychological, and biological variables contribute very little to an understanding of fertility differentials among the British, the French and 'other' ethnic groups. Considering the size of the effects given in Appendix 2 one could conclude sociopsychological factors (4 out of 8 coefficients) contribute, slightly more, to understand ethnic differences in fertility followed by biological ( 3 out of 8 coefficients) and socioeconomic factors ( 2 out of 8 coefficients). Moreover, ethnicity has different consequences for women married recently than for those married for a longer period of time. Surprisingly, among the recently married women, ethnicity per se not only increases fertility, but interacts with other variables to maintain higher levels of reproduction than those shown for the British. Among the respondents married for $14+$ years the interaction tends to minimize in family size. But the examination of the effects of individual variables suggests the presence of offsetting effects. Overall, a substantial portion of variance remains unexplained by the model, particularly for those married for a longer period of time. Similar conclusions are also reached from the decomposition analysis of religion. Biological factors appear as major explanators of religious differences in fertility. Even though, majority of the Catholics in the survey are of French ethnic origin, the interaction between ethnicity and religion was not significant in the preliminary analysis. 
Regarding region, the decomposition analysis suggests that there would be a sizable reduction in fertility if Atlantic women were to develop characteristics similar to women elsewhere in Canada. Further, region per se serves to raise fertility, but more so for women married for $14+$ years. It also interacts with other variables to increase the fertility of the latter and to decrease fertility of recently married women. The analysis reveals that biological factors play an important role in understanding regional differences in fertility.

The general conclusion that can be drawn from this study is that sociopsychological factors and, to some extend, socioeconomic factors are important in explaining ethnic differences in fertility, while the biological factors appear to be important in religious and regional differences in fertility. Fertility differentials by structural factors (ethnicity, religion, region, residence) do exist; but they are relatively smaller than in previous studies. Socioeconomic factors emerge as the least important component in fertility explanations. This lack of evidence can be attributed to errors involved in measuring a given concept rather than to the process itself. The subjective economic measures, suggested in other studies, do not seem to capture the realm of economic rationality involved in fertility decision-making process.

\section{Acknowledgments:}

This is a revised version of a paper presented at the 1997 Annual Meetings of the Population Association of America, March 27-29, Washington, D.C., USA. This paper is based on a Ph.D thesis submitted to the Department of Sociology at the University of Alberta. The author is indebted to Professors K. Krotki, F, Trovato, N.M. Lalu and M. Gillespie of the University of Alberta for their critical comments and helpful suggestions.

\section{Footnotes:}

1. A number of other variables were considered for the analysis but found not significant ( for example, nativity, husband's relative income, husband's occupations and family income).

2. For illustration purpose ethnicity is divided into two categories: British (B) and Other ethnic groups $(\mathrm{O})$.

3. Preliminary analysis suggested the presence of significant interactions between marital duration and other variables in the model. Therefore, the need for the adjustment for marital duration arises if the variation in this variable is substantial within a given age group across various socioeconomic groups. For example, marital duration is likely to vary 
more for younger than for older cohorts of women and, therefore, it is useful to present results after the adjustment for duration of marriage. The median value for marital duration is used to divide them into two groups.

4. Appendix 1 provides significant socioeconomic, sociopsychological and biological variables in multiple regression analysis for ethnicity, religion and region.

\section{References:}

Arnold, F., R.A. Bulatao., C. Buripakadi., B.J. Chung., J.T.Fawcett., T. Iritani., S.J. Lee., and T.-S. Wu. 1975. The Value of Children: Introduction and Comparative Analysis, Vol. I. Honolulu: East-West Population Institute.

Bachu, A. 1991. Profile of the Foreign-born population in the United States, Current Population Reports, Series p. 23, No. 176.

Bagozzi, Richard P. and M.F. Van Loo. 1980. Decision-making and fertility: a theory of exchange in the family, in T.K. Burch (ed.), Demographic Behavior: Interdisciplinary Perspectives on Decision-Making. Westview Press, Inc. Pp. 91-124.

Balakrishnan, T.R., G.E. Ebanks and C.F. Grindstaff. 1979. Patterns of Fertility in Canada, 1971. Ottawa: Statistics Canada, Catalogue No. 99-759E; 1971 Census Monograph.

Balakrishnan, T.R., Evelyn Lapierre-Adamcyck; and K.J. Krotki. 1994. Family Childbearing in Canada: A Demographic Analysis. Toronto: Univeersity of Toronto Press.

Becker, G.S. 1960. An economic analysis of fertility, in Demographic and Economic Change in Developed Countries. National Bureau of Committee for Economic Research. Princeton: Princeton University Press. Pp 209-231.

Blake, Judith. 1966. "Ideal family size among white Americans: a quarter of a century's evidence," Demography, 3: 154-173.

Blake, Judith. 1968. "Are babies consumer durables?" Population Studies, 22: 5-25.

Bongaarts, J. 1982. "The fertility-inhibiting effects of the intermediate fertility variables," Studies in Family Planning, Vol. 13(67): 179-89. 
Bulatao, R.A. 1981. "Values and disvalues of children in sequential childbearing decisions," Demography, 18: 1-26.

Bulatao, R.A. and James T. Fawcett. 1983. Influences on childbearing Intentions Across the Fertility Career: Demographic and Socioeconomic Factors and the Value of Children. Papers of the EastWest Population Institute. No.60-F.

Coleman, J.S., Z.D. Blum., A.B. Sovensen., and P.H. Rossi. 1972. "White and black careers during the first decade of labor force experience. Part I: occupational status,"Social Science Research, 1:243-270.

Davis, $\mathrm{K}$ and Judith Blake. 1956. "Social structure and fertility: an analytic framework," Economic Development and Cultural Change, 4(3): :211235.

Dumas, Jean. 1994. Report on the Demographic Situation in Canada 1993. Current Demographic Analysis. Cat. 91-209E Annual. Ottawa: Minister of Indutry, Science and Technology Canda.

Easterlin, R.A. 1975. "An economic framework for fertility analysis," Studies in Family Planning, 6: 54-63.

Fawcett, J.T.(ed.). 1972. The Satisfactions and Costs of Children: Theories, Concepts and Methods. Honolulu: East-West Population Institute.

Freedman, Deborah S. 1963. "The relation of economic status to fertility," The American Economic Review 53(June): 414-426.

Goldscheider, C. and W. Mosher. 1991. "Patterns of contraceptive use in the United States: The importance of religious factors," Studies in Family Planning 22(2): 102-15.

Goldscheider, F. and L. Waite. 1991. New Families, No Families: The Transformation of the American Home. Berkely and Los Angeles: University of California Press.

Halli, S.S. 1987. How Minority Status Affects Fertility: Asian Groups in Canada. Connecticut: Greenwood Press, Inc.

Hawthorne, G. 1970. The Sociology of Fertility. New York: Macmillan.

Henripin, Jacques. 1972. A fertility survey in Quebec. Unpublished paper presented at Population Association of America meetings. 
Hoffman, L.W. and M.L. Hoffman. 1973. The value of children to parents, in J.T. Fawcett (ed.), Psychological Perspectives on Population. New York: Basic Books. Ppp. 19-76.

Jiobu, R. and H. Marshall. 1977. "Minority status and family size: a comparison of explanations," Population Studies, 31: 509-517.

Johnson, N.E. and Ryoko Nishida. 1980. "Minority group status and fertility: a study of Japanese and Chinese in Hawaii and California," American Journal of Sociology, 86(3): 496-511.

Jones, E. and C. Westoff. 1979. "The end of Catholic fertility," Demography 16: 209-217.

Kupinsky, Stanley (ed.). 1977. The Fertility of Working Women: A Synthesis of International Research, New York: Praeger Publishers.

Leibenstein, H. 1957. Economic Backwardness and Economic Growth. John Wiley and Sons, New York.

Long, Larry H. 1970. "Fertility patterns among religious groups in Canada," Demography 7(2): 135-149.

Lorimer, F. 1954. Culture and Human Fertllity. Zurich:UNESCO, Paris.

Mathews, R. 1976. There's No Better Place Than Here: Social Change in Newfoundland Communities. Toronto: Peter Martin Associates.

McVey, W. W and W. E. Kalbach. 1995. Canadian Population. Toronto: Nelson Canada.

Mosher, William D. and Gerry E. Hendershot. 1984. "Religion and fertility: A replication." Demography 21(2): 185-191.

Pinelli, A. 1971. "Female labour and fertility in relationship to contrasting social and economic conditions," Human Relations 24: 603-610.

Ryder, N. 1990. "What is going to happen to American fertility?" Population and Development Review 16(3): 433-454.

Sabol, M.G. 1974. Commitment to work, in L.W. Hoffman and F.I. Nye (ed.), Working Mothers. San Francisco.

Saflios-Rothschild, C. 1972. "The relationship between work commitment and fertility," International Journal of Society of the Family, 2: 64-71. 
Scanzoni, J. 1975. Sex Roles, Life Styles, and Chidbearing. New York: Free Press.

Scanzoni, J.H. 1976. "Gender role and the process of fertility control," Journal of Marriage and the Family, 38:677-691.

Statistics Canada. 1993. 1991 Census of Canda, Fertility, The Nation, Cat. 93-321. Ottawa: Minister of Industry, Science and Technology. Table 6.

Suter, Larry E., L.J. Waite and R.M. Stolzenberg. 1976. Birth expectations and working plans of young women: changes in role choices. Paper presented at the P.A.A meetings.

Tremblay, V. and Guy Trudel. 1984. Canadian Fertility Survey: Methodological Report. Montreal: Universite de Montreal.

Trovato, F. and T.K. Burch. 1980. "Minority group status and fertility in Canada," Canadian Ethnic Studies 12:1-18.

Trovato, F. and S.S. Halli. 1983. "Regional differences in family size: the case of the Atlantic provinces in Canada," Rural Sociology, 48(2): 271-290.

Turchi, Boone A. 1975b. The Demand for Children in the U.S. Ballinger Press.

Vance, Rupert B. 1952. "Is theory for demographers?" Social Forces 31(1): 9-13.

Veevers, J.E. 1983. Demographic Aspects of Vital Statistics: Fertility. Ottawa: Statistics Canada, Catalogue No. 84-X-501E.

Williams, L. and B. Zimmer. 1990. "The changing influence of religion on U.S. fertility: evidence from Rhode Island," Demography 27(3): 475-81.

Received June 1998; Revised February 2000 
Appendices:

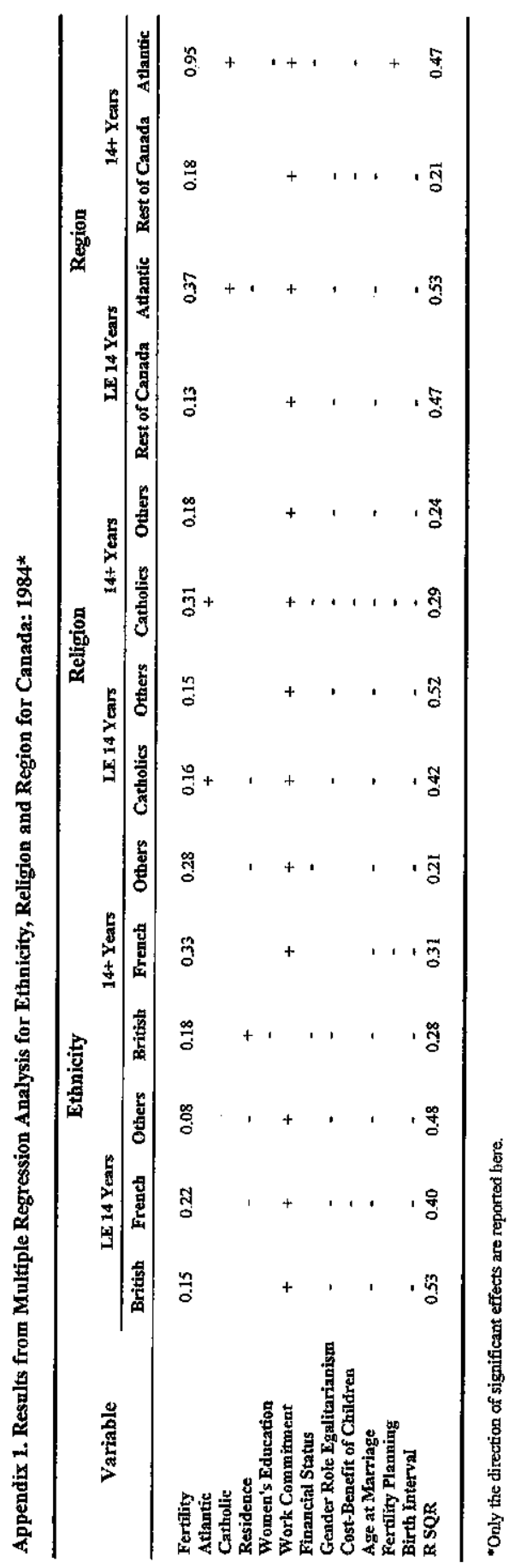




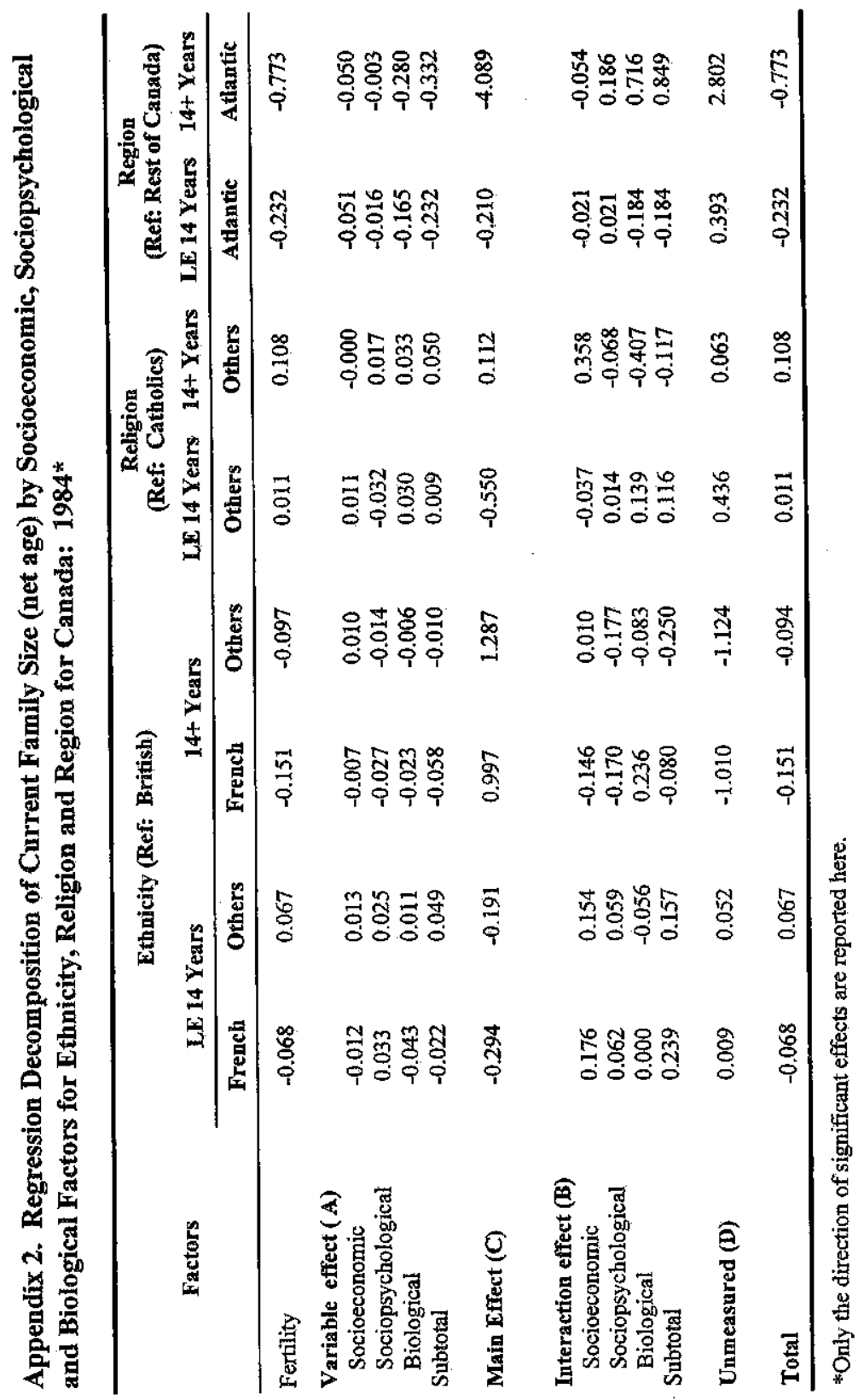

